\title{
Using the (Region of Interest ROI) Option of Magnetic Resonance Imaging (MRI) to Distinguish between Multiple Sclerosis (MS) and Ischemic Plaques in the Central Nervous System (CNS)
}

\author{
Ali Abd Sulaiman', Nabaa A. Naji ${ }^{2}$, Mona Abdul-Ghani Al-Rawi ${ }^{3}$ \\ ${ }^{1}$ MSc. Medical Physicist, College of Medicine, Al-Mustansiryah University \\ aliabd85.physics[at]gmail.com \\ ${ }^{2} \mathrm{PhD}$, Medical Physicist, College of Medicine, Al-Mustansiryah University \\ Nabaanaji2012[at]gmail.com \\ ${ }^{3}$ MB, ChB, F.A.C.M.S, Consultant Radiologist, College of Medicine, Al-Mustansiriyah University \\ alrawi_amir[at]yahoo.com
}

\begin{abstract}
Background: Magnetic Resonance Imaging is a device used in neurological examination, "it uses a combination of a strong magnetic field and radio waves to produce detailed pictures of the inside of the body" and can be used for the diagnosis of MS and Ischemia in brain. Studies of different MRI techniques were done to examine the diagnostic accuracy of MS and Ischemia separately. Some of these techniques depended the quantitative susceptibility mapping which used the T2W and T1W with contrast sequences where their susceptibility values were measured in MS disease, "while other study of a multi-spectral classification approach compared against mono-spectral classification performance using only FLAIR MRI datasets and two sets of expert segmentations were used for interobserver agreement evaluation in Ischemia disease”. There is no previous research which uses the ROI option of the MRI software to examine the best MRI sequence which provides a signal intensity reader that can distinguish between MS and Ischemia. Patients and method: This study involved 100 patients who were diagnosed as having brain Ischemia and 76 who have MS. "Imaging was performed on a 3T Philips MR system using T1W turbo spin echo (T1W_TSE) with and without contrast, fluid attenuated inversion recovery (FLAIR), and T2W turbo spin echo (T2W_TSE) sequences with the same parameters for both diseases that includes: field of view (FOV), image's matrix, slice thickness, voxel size, and number of signal averaging (NSA) " and reading signal intensity by ROI option in MRI software. Result: The data of the current research showed that "there is a significant difference in the signal intensity of the T2W and T2W.FLAIR sequences between Ischemia and MS". It was found that there was a noticeable significant increase in the signal of $\left(T 2 W_{\text {min, max, mean }}\right)$ and $\left(T 2 W . F L A I R_{\text {min, max, mean }}\right)$ in $M S$ disease as compared with the same values of Ischemia $(P<0.009,0.001,0.002)$ respectively $(P<0.0001)$. Using the $T 1 W_{\min , \max \text {, mean }}$ sequence with contrast provided a very strong significance in showing the active MS lesions $(P<0.0001)$. The four MRI sequences efficiency for distinguishing MS lesions from Ischemia were examined and the results analysis by the AUC indicated the priority of T2W. FLAIR in detecting the MS rather than Ischemia $(A U C=0.840)$. Conclusion: T2W.FLAIR sequence is the best for differentiation between MS and Ischemia plaques of the brain where the MRI signal intensity reading was read by the Region of Interest option of the MRI device software. Moreover, TIW with contrast is considered as an excellent indicator for the active $M S$.
\end{abstract}

Keywords: MRI, MS, Ischemia, T1W, T2W, FLAIR and T1W with contrast sequences

\section{Introduction}

MRI in Neurological examination combines a strong magnetic field and radiofrequency energy to produce detailed pictures of the inside of the body by studying the distribution and behavior of Hydrogen proton in fat and water"[4]The nervous system is the most important part in the human body. "It is divided into two main parts: the central nervous system (CNS) which consists of the brain and spinal cord, and the peripheral nervous system (PNC) [1] Multiple sclerosis (MS) is an inflammatory demyelinating disease of center nervous system (CNS). it's one of the most common central nervous system diseases" [2]. While, Ischemic ("is-skeem-ic") stroke occurs when an artery to the brain is blocked. The brain depends on its arteries to bring fresh blood from the heart and lungs. The blood carries oxygen and nutrients to the brain, and takes away carbon dioxide and cellular waste [3].
In this study we tried to find a MRI sequence that distinguishing between Multiple sclerosis and Ischemia, and active and non-active in MS by using the ROI option of the MRI software. .

\section{Patient and Method}

This study is a prospective clinical study that conducted in Al-Yarmouk teaching hospital/ MRI unit and the neuroscience hospital during the period from December 2016 to April 2017. It involves patients who were diagnosed by the neurologists and radiologists as having ischemia or MS. Patients' characteristics are shown in the following table: 


\section{International Journal of Science and Research (IJSR) \\ ISSN (Online): 2319-7064}

Index Copernicus Value (2016): 79.57 | Impact Factor (2015): 6.391

Table 1: Patients Characteristics

\begin{tabular}{|c|c|c|c|c|c|}
\hline Disease & Number & Male & Female & $\begin{array}{c}\text { Age } \\
\text { range } \\
(\mathbf{Y})\end{array}$ & $\begin{array}{c}\text { Mean } \pm \\
\text { SD }\end{array}$ \\
\hline Ischemia & 100 & 49 & 51 & $20-65$ & $\begin{array}{c}46.8 \pm \\
12.5\end{array}$ \\
\hline MS & 76 & 31 & 45 & $20-53$ & $\begin{array}{c}33.2 \pm \\
8.2\end{array}$ \\
\hline
\end{tabular}

\section{Examination Technique}

The range of signal intensity of the three sequences (T1W_TSE, T2W. FLAIR, and T2W_TSE) was measured by ROI (Region of Interest) option and recorded for each patient for data comparison purpose.

To Study the active and non-active M.S, twenty of the 76 patients presented with early MS symptoms were involved in this part of the research to distinguish between the active and non-active cases of brain M.S, these case were studied by using TIW sequence with and without I.V contrast injection $\left(\mathrm{Omniscan}{ }^{\mathrm{TM}} 0.5 \mathrm{mmol} / \mathrm{mL}\right)$. The range of signal intensity of $\mathrm{T} 1 \mathrm{~W}$ of both active and non-active M.S was recorded.

\section{Statistical Analysis}

Analysis of data was carried out using the available statistical package of SPSS-24 (Statistical Packages for Social Sciences- version 24). Data were presented in simple measures of frequency, percentage, mean, standard deviation, and range (minimum-maximum values). The significance of difference of different means (quantitative data) were tested using Students-t-test for difference between two independent means or Paired-t-test for difference of paired observations (or two dependent means), or ANOVA test for difference among more than two independent means. The significance of difference of different percentages (qualitative data) were tested using Pearson Chi-square test ( $\chi 2$-test) with application of Yate's correction or Fisher Exact test whenever applicable. Pearson correlation was calculated for the correlation between two quantitative variables with its t-test for testing the significance of correlation. The correlation coefficient value ( $r$ ) either positive (direct correlation) or negative (inverse correlation) with value $<0.3$ represent no correlation, $0.3-<0.5$ represent weak correlation, $0.5-<0.7$ moderate strength, $>0.7$ strong correlation. In addition to correlation the $\mathrm{r} 2$ was calculated (The coefficient of determination), i.e. when value of $\mathrm{r}=0.58$, then $\mathrm{r} 2=0.34$, this means that $34 \%$ of the variation in the values of $y$ may be accounted for by knowing values of $\mathrm{x}$ or vice versa. Statistical significance was considered whenever the $\mathrm{P}$ value was equal or less than 0.05

\section{Results}

\subsection{Signal intensity of $\mathrm{T} 2 \mathrm{~W}$ sequence in Ischemia and MS}

The data of the current research showed that there is a significant difference in the signal intensity of T2W sequence between Ischemia and MS. It was found that there was a noticeable significant increase in the minimum, maximum and mean values of $\mathrm{T} 2 \mathrm{~W}$ signal in the case of MS disease as compared with the same values of Ischemia as shown in table 2 and figure 1 . The highest signal intensity increase was found in the mean value of $\mathrm{T}_{2} \mathrm{~W}_{\max }$ in MS case as shown in figure 2. The of mean value showing a significant increase in the intensity signal of MS as compared with Ischemia as shown in table (2).

Table 2: Signal intensity of T2W sequence in Ischemia and MS

\begin{tabular}{|c|c|c|c|}
\hline T2W & Ischemia Mean \pm SD Range & MS Mean \pm SD Range & P value \\
\hline \multirow{2}{*}{ T2W Min } & $\begin{array}{c}820.8 \pm 99.3 \\
(569-1101)\end{array}$ & $\begin{array}{c}854.8 \pm 58.5 \\
(730-1010)\end{array}$ & $0.009 *$ \\
\hline \multirow{2}{*}{ T2W Max } & $\begin{array}{c}1066.9 \pm 122.2 \\
(745-1448)\end{array}$ & $\begin{array}{c}1119.6 \pm 75.6 \\
(875-1272)\end{array}$ & $0.001 *$ \\
\hline \multirow{2}{*}{ T2W Mean } & $\begin{array}{c}943.9 \pm 107.6 \\
(668.5-1274.5)\end{array}$ & $\begin{array}{c}987.2 \pm 57.2 \\
(812.5-1107.5)\end{array}$ & $0.002 *$ \\
\hline \multirow{2}{*}{ T2W Range } & $\begin{array}{c}246.1 \pm 57.3 \\
(110-403)\end{array}$ & $(125-424)$ & 0.057 \\
\hline \multicolumn{2}{|c|}{$*$ Significant difference between two independent means using Students-t-test at 0.05 level. } \\
\hline
\end{tabular}

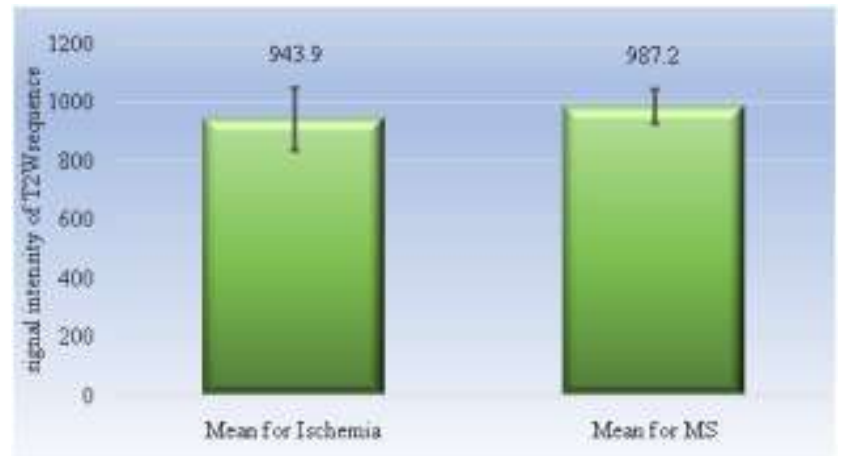

Figure 1: A comparison between the signal intensity of $\mathrm{T}_{2} \mathrm{~W}_{\text {mean }}$ in Ischemia and MS

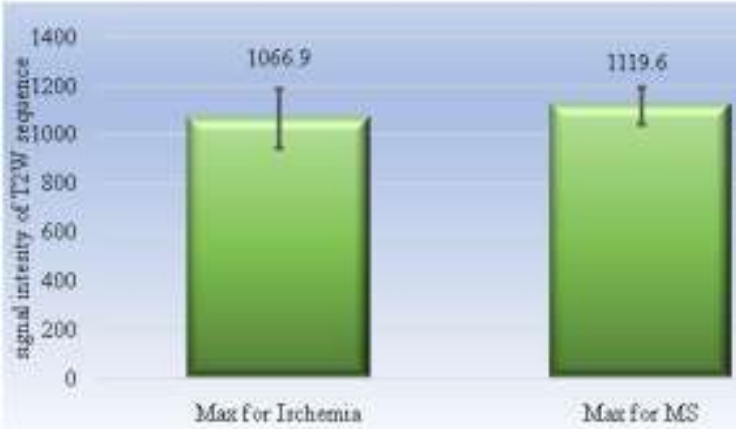

Figure 2: A comparison between the signal intensity of $\mathrm{T}_{2} \mathrm{~W}_{\max }$ in Ischemia and MS

Volume 6 Issue 12, December 2017 


\section{International Journal of Science and Research (IJSR) \\ ISSN (Online): 2319-7064}

Index Copernicus Value (2016): 79.57 | Impact Factor (2015): 6.391

\subsection{Signal intensity of T2W.FLAIR sequence in} Ischemia and MS

In this study, a strong significant difference appeared in the minimum, maximum and mean signal intensity of T2W. FLAIR sequence between Ischemia and MS, where the signal intensity of T2W.FLAIR min, T2W.FLAIR max., and T2W.FLAIR mean were significantly highest in MS. Adding to that, the mean of T2W.FLAIR range showed a significant higher value in MS as compared to Ischemia as shown in table 3 and figures 3 and.4.

Table 3: Signal intensity of T2W.FLAIR sequence in Ischemia and MS

\begin{tabular}{|c|c|c|c|}
\hline T2W.FLAIR & $\begin{array}{c}\text { Ischemia } \\
\text { Mean } \pm \text { SD } \\
\text { Range }\end{array}$ & $\begin{array}{c}\text { MS } \\
\text { Mean } \pm \text { SD } \\
\text { Range }\end{array}$ & P value \\
\hline $\begin{array}{c}\text { T2W.FLAIR } \\
\text { Min }\end{array}$ & $\begin{array}{c}970.9 \pm 115.2 \\
(685-1298)\end{array}$ & $\begin{array}{c}1074.8 \pm 93.3 \\
(890-1205)\end{array}$ & $0.0001 *$ \\
\hline $\begin{array}{c}\text { T2W.FLAIR } \\
\text { Max }\end{array}$ & $\begin{array}{c}1291.3 \pm 145.6 \\
(980-1589)\end{array}$ & $\begin{array}{c}1432.2 \pm 103.3 \\
(1179-1630)\end{array}$ & $0.0001 *$ \\
\hline T2W.FLAIR & $\begin{array}{c}1131.1 \pm 122.6 \\
(832.5- \\
\text { Mean }\end{array}$ & $\begin{array}{c}1253.5 \pm 88.1 \\
(1034.5-\end{array}$ & $0.0001 *$ \\
\hline T2W.FLAIR & $\begin{array}{c}320.4 \pm 94.1 \\
(111-494)\end{array}$ & $\begin{array}{c}357.4 \pm 87.7 \\
(178-583)\end{array}$ & $0.008^{*}$ \\
Range & *Significant difference between two independent means using \\
\multicolumn{4}{|c|}{ Students-t-test at 0.05 level. } \\
\hline
\end{tabular}

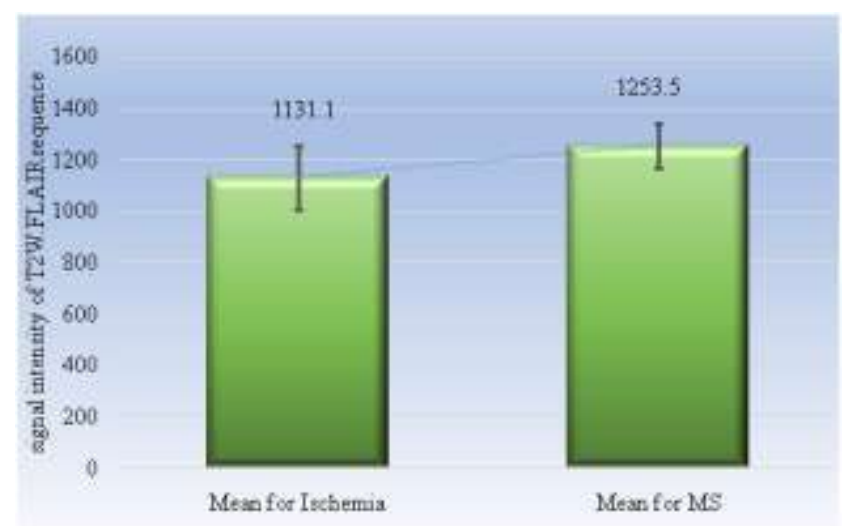

Figure 3: A comparison between the signal intensity of T2W.FLAIR ${ }_{\text {mean }}$ in Ischemia and MS

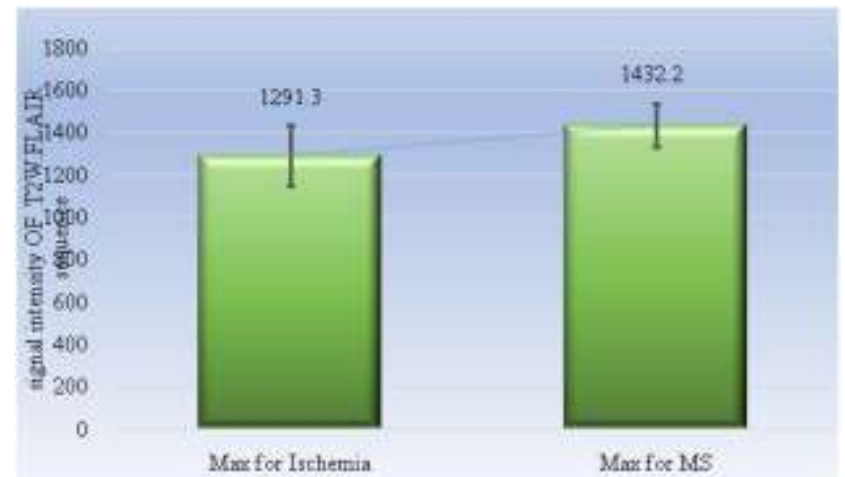

Figure 4: A comparison between the signal intensity of

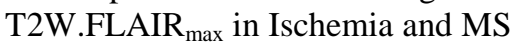

\subsection{Signal intensity of T1W sequence in Ischemia and MS}

The findings of the current study showed that there wasn't any significant difference in the signal intensity parameters of the T1W sequence between Ischemia and MS as shown in table 4.

Table 4: Signal intensity of T1W. sequence in Ischemia

\begin{tabular}{|c|c|c|c|}
\hline \multicolumn{5}{|c|}{ and MS } \\
T1W & $\begin{array}{c}\text { Ischemia } \\
\text { Mean } \pm \text { SD } \\
\text { Range }\end{array}$ & $\begin{array}{c}\text { MS } \\
\text { Mean } \pm \text { SD } \\
\text { Range }\end{array}$ & $\begin{array}{c}\mathrm{P} \\
\text { value }\end{array}$ \\
\hline T1W Min & $\begin{array}{c}724.2 \pm 140.4 \\
(401-997)\end{array}$ & $\begin{array}{c}738.9 \pm 93.8 \\
(529-997)\end{array}$ & 0.431 \\
\hline T1W Max & $\begin{array}{c}793.8 \pm 141.3 \\
(473-1102)\end{array}$ & $\begin{array}{c}808.7 \pm 93.7 \\
(631-1070)\end{array}$ & 0.425 \\
\hline T1W Mean & $\begin{array}{c}759.0 \pm 140.1 \\
(437-1034)\end{array}$ & $\begin{array}{c}773.8 \pm 93.5 \\
(588-1033.5)\end{array}$ & 0.426 \\
\hline T1W Range & $\begin{array}{c}69.6 \pm 27.1 \\
(27-155)\end{array}$ & $\begin{array}{c}69.8 \pm 14.1 \\
(40-118)\end{array}$ & 0.938 \\
\hline *Significant difference between two independent means using \\
Students-t-test at 0.05 level. \\
\hline \multicolumn{4}{|c|}{}
\end{tabular}

\subsection{Signal intensity of T1W sequence with and without} contrast in MS diagnosis:

The results of the current research revealed a significant increase in the signal intensity of the $\mathrm{T} 1 \mathrm{~W}_{\min }, \mathrm{T}_{1} \mathrm{~W}_{\max }$, and $\mathrm{T} 1 \mathrm{~W}_{\text {mean }}$ when a contrast media was used for the diagnosis of MS. A significant increase in the mean of $\mathrm{T}_{1} \mathrm{~W}_{\text {range }}$ was also found by using the contrast media as shown in table 5 and figures 5 and 6.

Table 5: Signal intensity of T1W. sequence with and without contrast in MS

\begin{tabular}{|c|c|c|c|}
\hline T1W & $\begin{array}{c}\text { Without contrast } \\
\text { Mean } \pm \text { SD } \\
\text { Range }\end{array}$ & $\begin{array}{c}\text { With contrast } \\
\text { Mean } \pm \text { SD } \\
\text { Range }\end{array}$ & P value \\
\hline T1W & $\begin{array}{c}725.3 \pm 89.3 \\
(529-903)\end{array}$ & $\begin{array}{c}1029.2 \pm 69.3 \\
(894-1176)\end{array}$ & $0.0001^{*}$ \\
\hline Min & $\begin{array}{c}795.2 \pm 85.7 \\
(631-968)\end{array}$ & $\begin{array}{c}1306.5 \pm 74.3 \\
(1167-1441)\end{array}$ & $0.0001^{*}$ \\
Max & $\begin{array}{c}760.2 \pm 87.1 \\
(588-935.5)\end{array}$ & $\begin{array}{c}1167.8 \pm 68.9 \\
(1030.5-1308.5)\end{array}$ & $0.0001^{*}$ \\
\hline T1W & $\begin{array}{c}69.9 \pm 17.9 \\
(47-118)\end{array}$ & $\begin{array}{c}277.3 \pm 40.9 \\
(216-371)\end{array}$ & $0.0001^{*}$ \\
\hline T1W & Range & &
\end{tabular}

*Significant difference between two dependent means using Paired-t-test at 0.05 level.

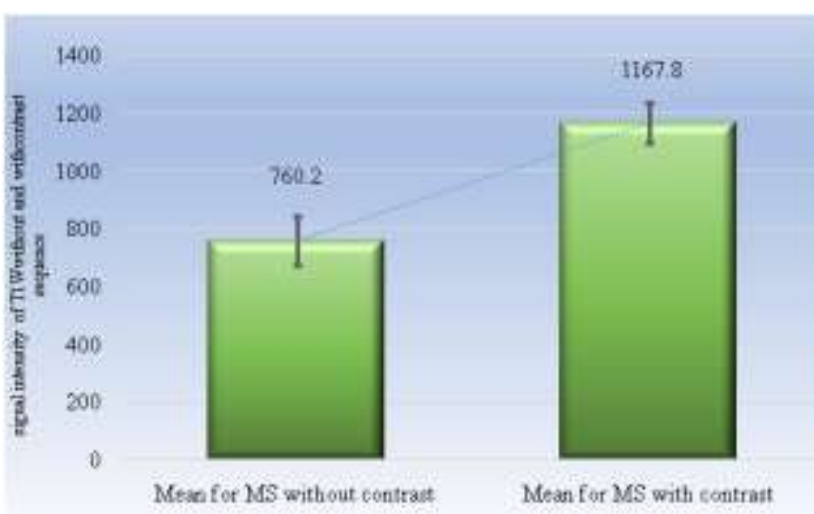

Figure 5: A comparison between the signal intensity of $\mathrm{T}_{1} \mathrm{~W}_{\text {mean }}$ with and without contrast in MS

Volume 6 Issue 12, December 2017 


\section{International Journal of Science and Research (IJSR) \\ ISSN (Online): 2319-7064}

Index Copernicus Value (2016): 79.57 | Impact Factor (2015): 6.391

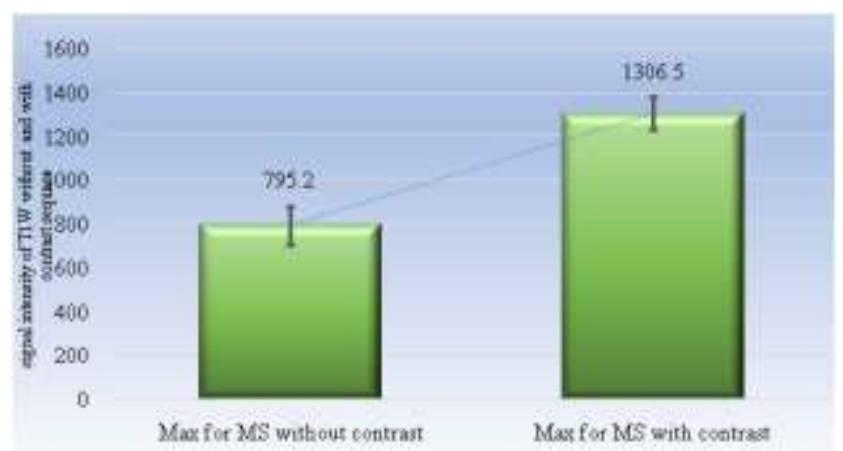

Figure 6: A comparison between the signal intensity of $\mathrm{T}_{1} \mathrm{~W}_{\max }$ with and without contrast in MS

3.5 Examining the efficiency of MRI sequences in determining Ischemia and MS:

3.5.1 Range of minimum, maximum, mean signal intensity of $\mathrm{T} 2 \mathrm{~W}$ sequence:

In the current study, the results of diagnosis accuracy test showed that the signal intensities of $\mathrm{T} 2 \mathrm{~W}_{\mathrm{Min}}, \mathrm{T} 2 \mathrm{~W}_{\mathrm{Max}}$, and $\mathrm{T} 2 \mathrm{~W}_{\text {Mean }}$ were not accurate in determining MS, in spite of the significant difference that was found between MS and Ischemia. They were considered as poor indicators for distinguishing between MS and Ischemia. While the T2W Range showed a failure in determining MS as shown in figure 7 and table 6 .

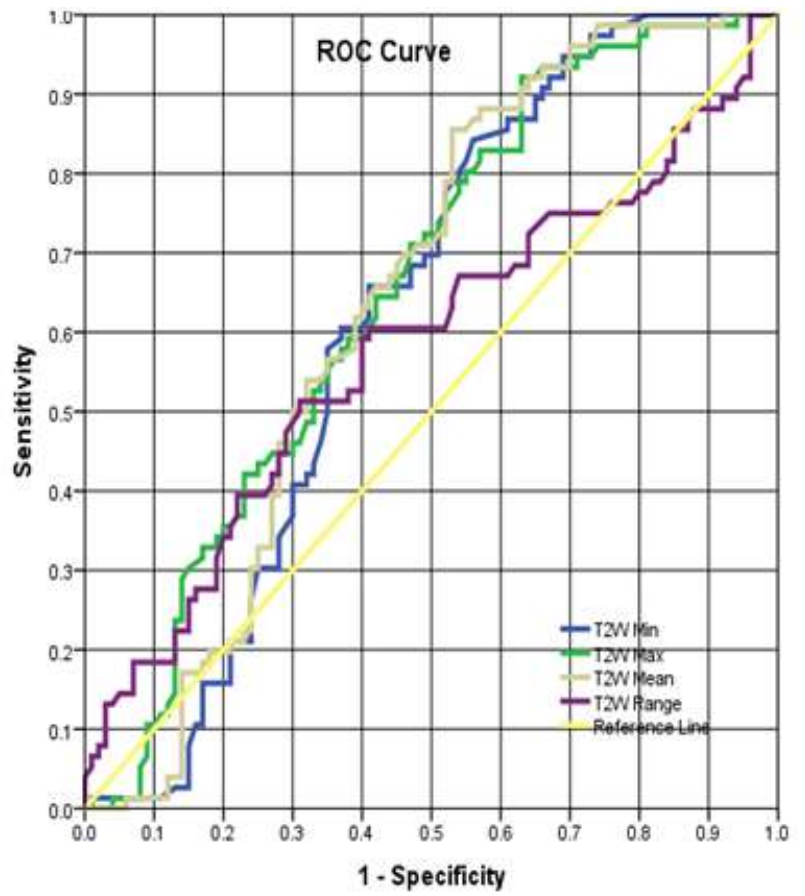

Figure 7: Accuracy of T2W sequence in determining MS and Ischemia

Table 6: Signal intensity accuracy test of $\mathrm{T} 2 \mathrm{~W}$ for determining MS and Ischemia

\begin{tabular}{|c|c|c|c|c|}
\hline \multirow{2}{*}{$\begin{array}{c}\text { Test Result } \\
\text { Variable(s) }\end{array}$} & \multirow{2}{*}{ AUC } & \multirow{2}{*}{ P value } & \multicolumn{2}{|c|}{ 95\% Confidence Interval } \\
\cline { 4 - 5 } & & & Lower Bound & Upper Bound \\
\hline $\mathrm{T}_{2} \mathrm{~W}_{\text {Min }}$ & 0.620 & $0.006^{*}$ & 0.538 & 0.703 \\
\hline $\mathrm{T}_{2} \mathrm{~W}_{\text {Max }}$ & 0.651 & $0.001^{*}$ & 0.571 & 0.731 \\
\hline $\mathrm{T}_{2} \mathrm{~W}_{\text {Mean }}$ & 0.638 & $0.002^{*}$ & 0.556 & 0.719 \\
\hline $\mathrm{T}_{2} \mathrm{~W}_{\text {Range }}$ & 0.579 & 0.073 & 0.491 & 0.666 \\
\hline
\end{tabular}

3.5.2 Range of minimum, maximum, mean signal intensity of T2W.FLAIR sequence:

The results of T2W FLAIR Min, T2W FLAIR Max $_{\text {andT2W }}$ FLAIR $_{\text {Mean }}$ showed a fair accuracy indication of MS where the AUC of these values were within this range of evaluation in spite of the high significant differences noticed between MS and Ischemia. The T2W FLAIR Range gave a failed indictor in determining MS as shown in figure 8 and table 7 .

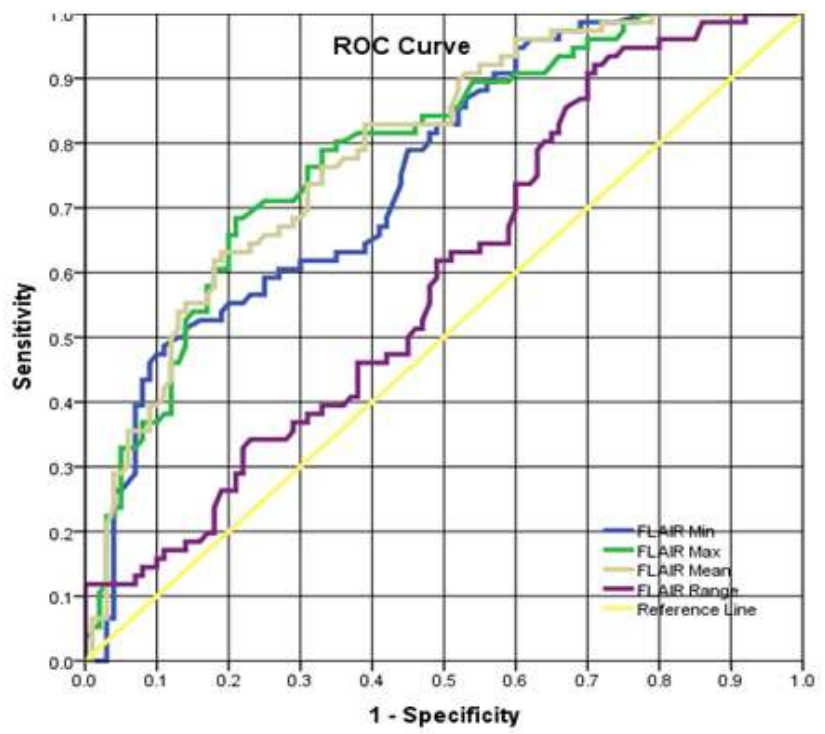

Figure 8: Accuracy of T2W.FLAIR sequence in determining MS and Ischemia

Table 7: Signal intensity accuracy test of T2W.FLAIR for determining MS and Ischemia

\begin{tabular}{|c|c|c|c|c|}
\hline $\begin{array}{c}\text { Test Result } \\
\text { Variable(s) }\end{array}$ & AUC & \multirow{2}{*}{ P value } & \multicolumn{2}{|c|}{$95 \%$ Confidence Interval } \\
\cline { 4 - 5 } & & & Lower Bound & Upper Bound \\
\hline T2W.FLAIR $_{\text {Min }}$ & 0.752 & $0.0001 *$ & 0.682 & 0.823 \\
\hline T2W.FLAIR $_{\text {Max }}$ & 0.785 & $0.0001 *$ & 0.717 & 0.852 \\
\hline T2W.FLAIR $_{\text {Mean }}$ & 0.788 & $0.0001 *$ & 0.722 & 0.854 \\
\hline T2W.FLAIR Range & 0.592 & $0.037 *$ & 0.508 & 0.676 \\
\hline
\end{tabular}

3.5.3 Range of minimum, maximum, mean signal intensity of $\mathrm{T1W}$ sequence without using a contrast media:

The findings of T1W signal intensity showed a failure in determining the incidence of MS and Ischemia where $\mathrm{T} 1 \mathrm{w}_{\mathrm{Min}}, \mathrm{T} 1 \mathrm{~W}_{\mathrm{Max}}$, and $\mathrm{T} 1 \mathrm{~W}_{\text {mean }}$ and $\mathrm{T} 1 \mathrm{~W}_{\text {Range }}$ were within the failure range of evaluation for their area under the curves, in addition to the weak significant difference of these values between MS and Ischemia as shown in figure 9 and table 8. 


\section{International Journal of Science and Research (IJSR) \\ ISSN (Online): 2319-7064}

Index Copernicus Value (2016): 79.57 | Impact Factor (2015): 6.391

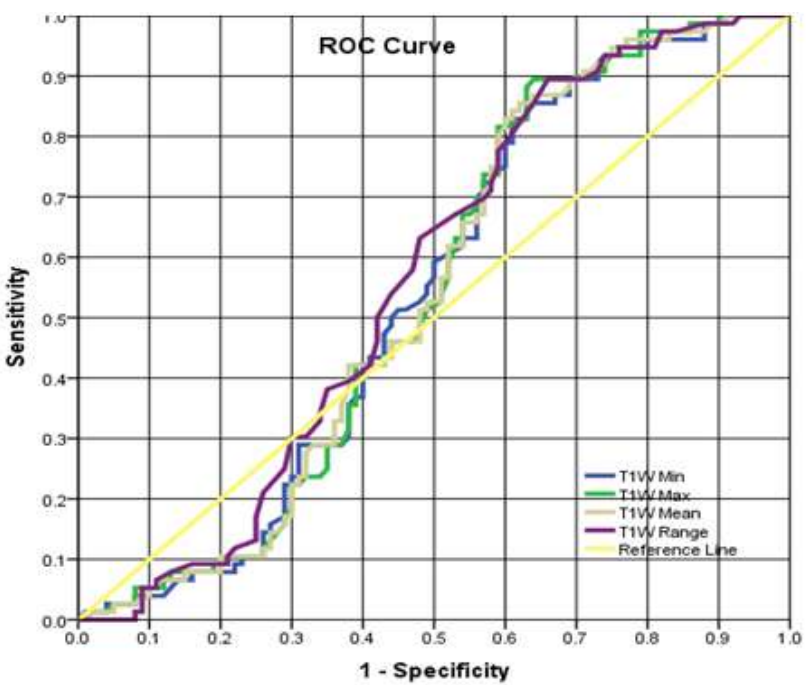

Figure 9: Accuracy of T1Wwithout contrast sequence in determining MS and Ischemia

Table 8: Signal intensity accuracy test of T1W for determining MS and Ischemia

\begin{tabular}{|c|c|c|c|c|}
\hline \multirow{2}{*}{ Test Result Variable(s) } & \multirow{2}{*}{ AUC } & \multirow{2}{*}{ P value } & \multicolumn{2}{|c|}{ 95\% Confidence Interval } \\
\cline { 4 - 5 } & & & Lower Bound & Upper Bound \\
\hline T1W Min & 0.541 & 0.358 & 0.455 & 0.626 \\
\hline T1W $_{\text {Max }}$ & 0.540 & 0.365 & 0.454 & 0.625 \\
\hline T1W Mean & 0.541 & 0.350 & 0.456 & 0.627 \\
\hline T1W $_{\text {Range }}$ & 0.562 & 0.159 & 0.477 & 0.647 \\
\hline
\end{tabular}

3.5.4 Range of minimum, maximum, mean signal intensity of $\mathrm{T} 1 \mathrm{~W}$ sequence with using a contrast media:

By using the contrast media in evaluating the efficiency of T1W sequence in determining the MS incidence, the findings showed excellent results in expressing the active MS with a strong significant difference of the evaluated parameters of this sequence as shown in figure 10 and table 9.

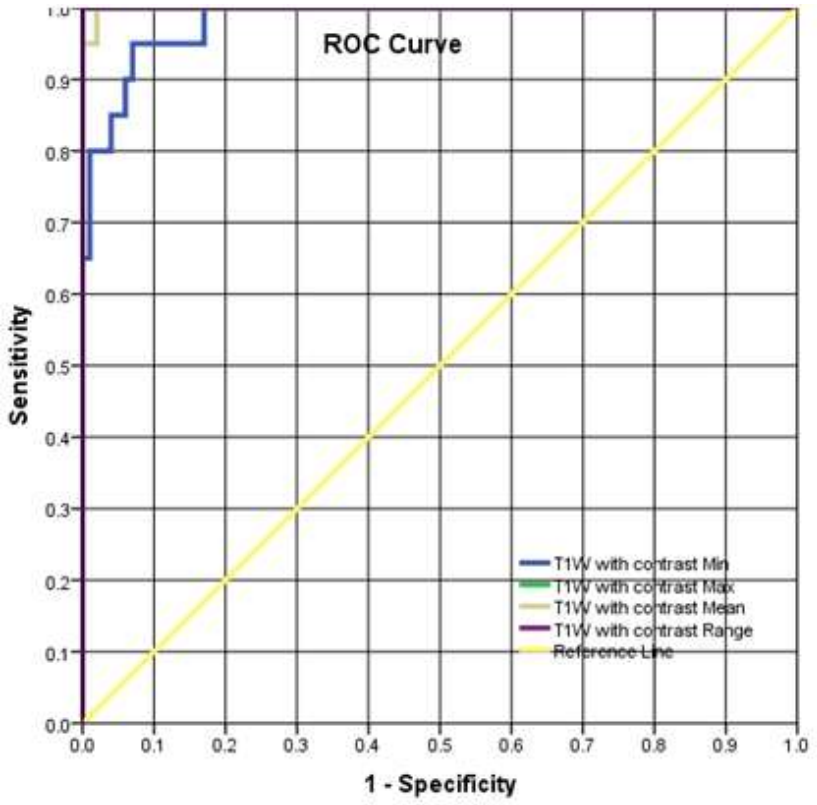

Figure 10: Accuracy of T1Wwith contrast sequence in determining MS
Table 9: Signal intensity accuracy test of T1W with contrast for determining MS

\begin{tabular}{|c|c|c|c|c|}
\hline \multirow{2}{*}{ Test Result Variable(s } & \multirow{2}{*}{ AUC } & \multirow{2}{*}{ P value } & \multicolumn{2}{|c|}{$95 \%$ Confidence Interval } \\
\cline { 4 - 5 } & & Lower Bound & Upper Bound \\
\hline T1W with contrast Min & 0.982 & $0.0001 *$ & 0.960 & 1.000 \\
\hline T1W with contrast Max & 1.000 & $0.0001 *$ & 1.000 & 1.000 \\
\hline T1W with contrast Mear & 0.999 & $0.0001 *$ & 0.996 & 1.000 \\
\hline $\begin{array}{c}\text { T1W with contrast } \\
\text { Range }\end{array}$ & 1.000 & $0.0001 *$ & 1.000 & 1.000 \\
\hline
\end{tabular}

3.6 A comparison among $T 2 W$, T2W. FLAIR, T1W without contrast, and $\mathrm{T} 1 \mathrm{~W}$ with contrast sequences for determining MS and Ischemia:

To identify the range of signal intensity of the most efficient MRI sequence for detecting MS and Ischemia, a comparison among the mean of these sequences was done. The results of this comparison pointed that the mean signal intensity of T2W.FLAIR was a good indicator for determining MS as compared with the other sequences. Moreover, the mean of signal intensity of T2W.FLAIR showed a highly significant difference among the used sequences in the detection of MS. On the other hand, the mean signal intensity of T1W sequence with contrast was found to be as an another excellent indicator for MS according to the range of evaluation for its AUC.

The mean signal intensity of $\mathrm{T} 2 \mathrm{~W}$ sequence reflected a poor result in determining MS, while the mean signal intensity of $\mathrm{T} 1 \mathrm{~W}$ sequence without contrast indicated a failed detection for MS as shown in figure 11 and table 10.

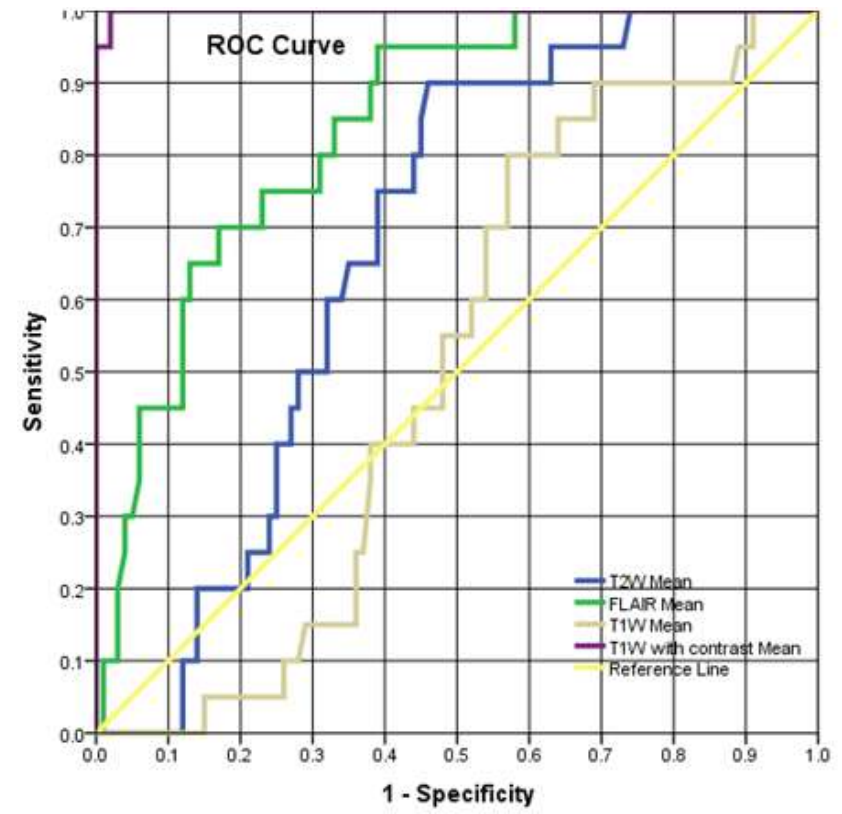

Figure 11: Accuracy of $\mathrm{T} 2 \mathrm{~W}_{\text {Mean }}, \mathrm{T} 2 \mathrm{~W} . \mathrm{FLAIR}_{\text {Mean }}$, $\mathrm{T} 1 \mathrm{~W}_{\text {Mean }}$, and $\mathrm{T} 1 \mathrm{~W}$ with contrast ${ }_{\text {Mean }}$ sequence in determining MS and Ischemia 


\section{International Journal of Science and Research (IJSR) \\ ISSN (Online): 2319-7064}

Index Copernicus Value (2016): 79.57 | Impact Factor (2015): 6.391

Table 10: Signal intensity accuracy test of T2W Mean, T2W.FLAIR Mean, T1W Mean and T1W with contrast Mean for determining MS and Ischemia

\begin{tabular}{|c|c|c|c|c|}
\hline \multirow{2}{*}{ Test Result Variable(s) } & \multirow{2}{*}{ AUC } & \multirow{2}{*}{ P value } & \multicolumn{2}{|c|}{ 95\% Confidence Interval } \\
\cline { 4 - 5 } & & & Lower Bound & Upper Bound \\
\hline T2W Mean & 0.675 & $0.014^{*}$ & 0.575 & 0.776 \\
\hline T2W.FLAIR Mean & 0.840 & $0.0001^{*}$ & 0.757 & 0.922 \\
\hline T1W Mean & 0.510 & 0.894 & 0.398 & 0.621 \\
\hline T1W with contrast & 0.999 & $0.0001 *$ & 0.996 & 1.000 \\
\hline
\end{tabular}

\section{Discussion}

\section{Signal intensity of T2W.FLAIR sequence in Ischemia and MS}

"The highly significant increase in the values of T2W.FLAIR sequence which were found in the current study are in accordance with the results of Bachmann R. et al, 2006[6] and Hashemi RH.et al, 1995[7] who published that T2W.FLAIR is the optimum (native study) MRI imaging sequence for MS when using a 3 Tesla MRI with TE of $120 \mathrm{~ms}$, where these parameters are similar to the ones used in the current study". Applying the TE of 120ms leads to a significant increase in the contrast to noise ratio of the white mater lesion and therefore increasing the detectability of MRI and the image's spatial resolution. Moreover, the results of the current research are in parallel with Ge.Y., 2006[8] who stated that T2W.Flair is a better detector for the lesion occurs in the white and gray matters of brain in MS cases.

The clear increase in the ranges of TIW signal intensity that was noticed in this study by using the double doses Gadolinium of $0.5 \mathrm{mmol} / \mathrm{mL}$ as a contrast media for the diagnosis of active MS can be explained by the possible effect of age on the enhancement of MS lesions. Moreover, the size of MS lesion and disease modifying therapy as well as the stage of disease activity (inflammation, demyelination, axonal loss and gliosis) may contribute to image contrast enhancement and the successful characterization of the disease state. "The effect of size idea is supported by Bedell B. and Narayana P, 1998[9] who reported that MS lesions larger than $5 \mathrm{~mm}^{3}$ was clearly identified by using the automatic segmentation analysis for the gadolinium enhanced MS lesions which is the same technique that was used in the current research", where the author used this technique only to cover the MS lesion for identifying it while in the current study the signal intensity of MS lesions was read.

A comparison among T2W, T2W. FLAIR, T1W without contrast, and $\mathrm{T} 1 \mathrm{~W}$ with contrast sequences for determining MS and Ischemia:

The finding of the current research approved the efficiency of $\mathrm{T} 1 \mathrm{~W}$ with contrast sequence in detecting the active MS lesion by using the ROI option of the MRI software. "This result is in coordination with Pretorius PM, et al 2003[10], in the current study, a scanning time delay with a double dose I.V contrast injection was 15 min". in(Trip S. and Miller D., 2005[11]), an only 5 minute delay scanning after I.V contrast administration for enhancing T1 imaging scanning . Newly active enhancing lesions usually persist for a month on average, making them a useful marker for monitoring disease activity and triple dose gadolinium or combination with magnetization transfer imaging can both increase active lesion detection.

"Zhang Y. et, 2016[12] reported that T2W sequence is accurate for the identification of blood brain barrier leakage status rather than using the $\mathrm{T} 1 \mathrm{~W}$ sequence with contrast where the authors depended on the quantitative susceptibility mapping option of the MRI software"

The AUC analysis of the T1W without contrast indicated a failure of this sequence in determining MS and Ischemia. "This result can be explained by the appearance of area of low signal intensity as compared with the normal white matter which is known as black holes, such lesions when newly formed will either disappear with time, when it is thought they are caused by reversible edema or demyelination, or persist as chronic black holes, when it is thought they are caused by permanent axonal loss" (Trip S. and Miller D., 2005[11]).

The strong significance of T2W.FLAIR in detecting the MS which appears from data analysis of the current research and its priority over the $\mathrm{T} 2 \mathrm{~W}$ sequence is supported by the findings of Trip S. and Miller D., 2005[11] who reported that the T2W.FLAIR is a superior sequence for the detection of MS lesions, and periventricular lesions are often indistinguishable from the adjacent CSF which is also of high signal with T2 weighting

\section{Conclusion}

The sequenceT2W.FLAIR is the best native study to differentiation between MS and Ischemic plaques of the brain when the MRI signal intensity reading is achieved with the region of interest option of the MRI device software. Moreover, the sequenceT1W with contrast considered as an excellent sequence for distinguishing between active and non-active MS lesions

\section{References}

[1] Snell, R. S. Clinical Anatomy by Systems. Introduction. Philadelphia: Lippincott Williams \& Wilkins, 2007.

[2] Ted Munsat, MD. Multiple Sclorosis for the Practicing Neurologist, 2007.

[3] Bamford J, Sandercock P, Jones L et al (1987).The natural history of lacunar infarction. The Oxfordshire Community Stroke Project. Stroke 18:5

[4] Glasser, O.: Wilheim (1934). Conrad roentgen and the Early History of the Rays .Springfield, IL, Charles C Thamas

[5] Hajian-Tilaki K. Receiver Operating Characteristic (ROC) Curve Analysis for Medical Diagnostic Test Evaluation, Caspian J Intern Med. 2013 Spring;4(2):627-35.

[6] Bachmann R, Reilmann R, Schwindt W, Kugel H, Heindel W. FLAIR imaging for multiple sclerosis: a comparative MR study at 1.5 and 3.0 Tesla. EurRadiol 2006; 16: 915-921.

\section{Volume 6 Issue 12, December 2017}




\section{International Journal of Science and Research (IJSR) \\ ISSN (Online): 2319-7064}

Index Copernicus Value (2016): 79.57 | Impact Factor (2015): 6.391

[7] Hashemi RH, Bradly WG, Chen DY, et al. (1995) suspected multiple sclerosis: MR imaging with a thin-section fast FLAIR pulse sequence. Radiology 196:505-510

[8] Ge.Y. Multiple Sclerosis: The Role of MR Imaging American Journal of Neuroradiology June 2006, 27 (6) 1165-1176

[9] Bedell BJ, Narayana PA .automatic segmentation of gadolinium-enhanced multiple sclerosis lesion, 1998

[10] Pretorius PM, Quaghebeur G. The role of MRI in the diagnosis of MS. ClinRadiol 2003

[11] Trip S A and Mille D H. Imaging in multiple sclerosis, J Neurol Neurosurg Psychiatry, 2005

[12] Y.zhang, S.A. Gauthier, L. Tu, J.Cominale, G.C.-Y. Chen, C.A.Salutri, W. Zhu and Y.Wang. American Journal of Neuroradiology October 2016

Volume 6 Issue 12, December 2017

www.ijsr.net 